\title{
Evaluating role of parity in progress of labour and its outcome using modified WHO partograph
}

\author{
Nupur Shah*, Nandita Maitra, S. L. Pagi \\ Baroda Medical College, Vadodara, Gujarat, India \\ Received: 21 January 2016 \\ Revised: 22 January 2016 \\ Accepted: 20 February 2016 \\ *Correspondence: \\ Dr. Nupur Shah, \\ E-mail: nupurmshah@gmail.com \\ Copyright: (c) the author(s), publisher and licensee Medip Academy. This is an open-access article distributed under \\ the terms of the Creative Commons Attribution Non-Commercial License, which permits unrestricted non-commercial \\ use, distribution, and reproduction in any medium, provided the original work is properly cited.
}

\begin{abstract}
Background: The progress of labour and its outcome differ based on the parity. These can be graphically proven by using an inexpensive tool -the modified WHO partograph. The plotting also helps to early recognition and prevention of the complications of labour. The objective of the study was to study and compare the course of labour and its outcome in primigravidae and mutigravidae using a graphical tool-Modified WHO partograph.

Methods: The study was undertaken at SSG hospital, Baroda from August 2012 to July 2013. One hundred twenty four primigravidae and 124 multigravidae women were recruited according to defined inclusion and exclusion criteria. The progress of labour in active stage was assessed and plotted on Modified WHO partograph. The outcomes studied were: duration of active first stage and second stage, cervicometric progress, Incidence of labour augmentation, Incidence of operative delivery and neonatal outcome (Apgar score, NICU stay and birth weight).

Results: The duration of active first stage $(5.07 \mathrm{hrs})$ and second stage $(33.57 \mathrm{~min})$ was longer in primigravidae with a slower progress of labour as plotted on the Modified WHO partograph, than in multigravidae (3.78 hrs and 22.86 min respectively). The cervical dilatation rate in primigravidae was $1.22 \pm 0.287 \mathrm{~cm} / \mathrm{hr}$ which was slower than that of multigravidae $(1.65 \pm 0.408 \mathrm{~cm} / \mathrm{hr})$. There was also a higher rate of operative delivery in primigravidae $(16.93 \% \mathrm{vs}$ $3.22 \%$ ).

Conclusions: The results highlight that the modified WHO partograph worked as a useful tool in our population in comparing the progress of labour.
\end{abstract}

Keywords: Modified WHO partograph, Primigravidae, Multigravidae, Labour progress

\section{INTRODUCTION}

Intrapartum risk is based mainly on obstetric history, which is higher in primiparous women. Prolonged and obstructed labour is one of the preventable causes of maternal and perinatal mortality. Its prevention chiefly depends on the early recognition of possible Cephalopelvic disproportion and use of partograph which guides in timely referral or intervention. ${ }^{1}$ WHO modified the partograph for use in hospitals, where in the latent phase was excluded; plotting the graph started at $4 \mathrm{~cm}$ cervical dilatation. ${ }^{2,3}$ The choice of $4 \mathrm{~cm}$ was made to reduce the risk of interventions in multigravidae women with patulous cervices who were not yet in labour. ${ }^{3}$ In this study we have used modified WHO partograph to detect the differences in progress and outcomes of labour in primigravidae versus multigravidae.

\section{METHODS}

This study was undertaken at labour room of SSG hospital; Baroda from August 2012 to July 2013.The study included those consecutive primigravidae and multigravidae women who met the following relevant criteria:

Those who were $\geq 37$ weeks of gestation, $\geq 4 \mathrm{~cm}$ dilatation, in spontaneous labour, with cephalic 
presentation and singleton pregnancy were included in the study. On the other hand, those with previous uterine surgery, cephalopelvic disproportions, associated complications like Pre eclampsia, eclampsia, anaemia, premature rupture of membranes, antepartum hemorrhage, medical illness were excluded.

One hundred and twenty four primigravidae and 124 multigravidae women were recruited and there progress in active labour was plotted on Modified WHO partograph. The outcomes studied were: duration of active first stage and second stage, cervicometric progress, Incidence of labour augmentation, Incidence of operative delivery and neonatal outcome (Apgar score, NICU stay and birth weight).

The labour protocol carried out was as follows: Per vaginal examinations were carried out on admission, and at 4 hourly intervals or more frequently if needed. Maternal and fetal parameters were plotted on the modified WHO partograph in active labour. When the progress appeared normal on partograph no intervention was made. When the plot crossed the alert line the patient was immediately reassessed. Oxytocin augmentation was considered when the alert line was crossed or at 6 hours after admission if the uterine contractions were inadequate (defined as contractions of $<4$ per $10 \mathrm{~min}$ lasting for $<40 \mathrm{sec})$. When the plot crossed action line immediate intervention in form of caesarean section was done.

\section{Data entry and statistical analysis}

The patient details and the relevant outcome measures were entered in an excel sheet (Microsoft excel windows 2007). For the quantitative variables: cervical dilatation rate, duration of active first stage and duration of second stage, statistical analysis by t test was performed.

\section{Ethics committee clearance}

The ethical clearance was obtained from the institutional ethics committee of the medical college and SSG hospital Baroda.

\section{RESULTS}

Table 1: Comparison of selected variables in primigravidae and multigravidae.

\begin{tabular}{|llll|}
\hline & primigravidae & multigravidae & $\begin{array}{l}\text { " } \mathrm{t} \text { " } \\
(\mathrm{p}<0.01)\end{array}$ \\
\hline $\begin{array}{l}\text { Mean } \\
\text { duration } \\
\text { of active } \\
\text { first } \\
\text { stage of }\end{array}$ & $5.07 \pm 1.24 \mathrm{hrs}$ & $3.78 \pm 1.16 \mathrm{hrs}$ & 8.17 \\
labour & & & \\
\hline $\begin{array}{l}\text { Mean } \\
\text { duration } \\
\text { of } \\
\text { second } \\
\text { stage }\end{array}$ & $33.57 \pm 9.50$ & $22.86 \pm 6.38$ & \\
\hline $\begin{array}{l}\text { Mean } \\
\text { cervical } \\
\text { dilatation }\end{array}$ & $1.22 \mathrm{~cm} / \mathrm{hr} \pm$ & $1.65 \mathrm{~cm} / \mathrm{hr} \pm$ & \\
rate & 0.287 & 0.408 & 9.247 \\
\hline
\end{tabular}

The mean duration of active first stage in primigravidae was $5.07 \pm 1.24 \mathrm{hrs}$ whereas the mean duration in multigravidae was $3.78 \pm 1.16 \mathrm{hrs}$ in present study. Mean

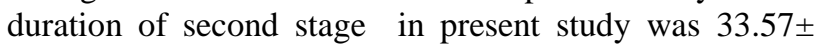
$9.50 \mathrm{~min}$ in primigravidae which was longer than in multigravidae where it is $22.86 \pm 6.38 \mathrm{~min}$.

The rate of augmentation in the present study was $43.68 \%$ in primigravidae $(n=124)$ and $16.6 \%$ in multigravidae $(n=120)$. The mean cervical dilatation rate in primigravidae is $1.22 \pm 0.287 \mathrm{~cm} / \mathrm{hr}$ and that in multigravidae was $1.65 \pm 0.408 \mathrm{~cm} / \mathrm{hr}$ which was faster than that of the former.

The rate of caesarean deliveries in primigravidae was $16.93 \%$ as compared to multigravidae $3.22 \%$. Overall caesarean section rate in this study was $10 \%$.Out of 21 primigravidae, 15 underwent caesarean section for fetal distress in $1^{\text {st }}$ stage, 3 for non-progression of $1^{\text {st }}$ stage and 3 for non-progression of second stage. Two of the 4 multigravidae delivered by caesarean were for fetal distress in $1^{\text {st }}$ stage, 1 for fetal distress in $2^{\text {nd }}$ stage and 1 for non-progression of $1^{\text {st }}$ stage of labour.

Table 2: Labour progress and outcome in primigravidae and multigravidae.

\begin{tabular}{|c|c|c|c|c|c|c|c|}
\hline & & \multicolumn{2}{|c|}{ Lefit to alert line $(n=168)$} & \multicolumn{2}{|c|}{ Between the two lines $(n=70)$} & \multicolumn{2}{|c|}{ Right to action line $(\mathrm{n}=9)$} \\
\hline & & $\begin{array}{l}\text { Primigravidae } \\
(\mathrm{n}=68)\end{array}$ & $\begin{array}{l}\text { Multigravidae } \\
(n=100)\end{array}$ & $\begin{array}{l}\text { Primigravidae } \\
(\mathrm{n}=49)\end{array}$ & $\begin{array}{l}\text { Multigravidae } \\
(\mathrm{n}=21)\end{array}$ & $\begin{array}{l}\text { Primigrav } \\
(n=6)\end{array}$ & $\begin{array}{l}\text { Multigravidae } \\
(n=3)\end{array}$ \\
\hline \multicolumn{2}{|c|}{ Augmented labour } & $13(19.11 \%)$ & 0 & $39(79.59 \%)$ & $19(90.47 \%)$ & $6(100 \%)$ & $1(33.33 \%)$ \\
\hline \multirow{2}{*}{$\begin{array}{l}\text { Mode } \\
\text { of } \\
\text { delivery }\end{array}$} & vaginal & $61(89.7 \%)$ & $99(99 \%)$ & $41(83.67 \%)$ & $20(65.23 \%)$ & 0 & $2(66.66 \%)$ \\
\hline & caesarean & $7(10.29 \%)$ & $1(1 \%)$ & $8(16.32 \%)$ & $1(4.7 \%)$ & $6(100 \%)$ & $1(33.33 \%)$ \\
\hline \multicolumn{2}{|c|}{ Neonatal asphyxia } & $4(5.88 \%)$ & $2(2 \%)$ & $6(12.24 \%)$ & 0 & 1 & 0 \\
\hline
\end{tabular}


There was no significant difference in the birth weights of neonates born to primigravidae and multigravidae. 11 neonates $(8.87 \%)$ were delivered to primigravidae and only $2(1.61 \%)$ neonates were delivered to multigravidae had an apgar score of ( $<7$ at $0,1,5 \mathrm{~min})$.

The neonatal NICU admission rate in primigravidae was $14.51 \%$ as compared to $3.22 \%$ in multigravidae. Out of the 18 neonates of primigravidae, 8 were only observed in NICU for 24 hours and then handed over to mother. Those admitted to NICU were due to the meconium associated with low apgar or respiratory distress.

\section{DISCUSSION}

The mean cervical dilatation rate in primigravidae was $1.22 \mathrm{~cm} / \mathrm{hr} \pm$ which is similar to the study of Freidmann et al $(1.2 \mathrm{~cm} / \mathrm{hr})$, Zhang et al $(1.1 \mathrm{~cm} / \mathrm{hr})$ and Neal et al $(1.2 \mathrm{~cm} / \mathrm{hr})^{8,10,11}$

In the study by Kunal Shinde et al carried out in the same racial population (i.e. India) as the present study with the use of Modified WHO partograph, the rates were similar to that of present study and that multigravidae $(1.7 \mathrm{~cm} / \mathrm{hr})$ progressed faster than primigravidae $(1.3 \mathrm{~cm} / \mathrm{hr}) .^{5} \mathrm{In}$ another study, Aboyeji et al had the rate $1.76 \mathrm{~cm} / \mathrm{hr}$ in primigravidae, which is higher than the present study. ${ }^{9}$ The difference may be due to the racial differences as the above study was carried out in the African population. Thus primigravidae have slower cervical dilatation rate than multigravidae.

The greater rate of caesarean deliveries in primigravidae $(16.93 \%$ vs $3.22 \%)$ in the present study was similar to the study carried out by Nazia hashim et al in Karachi $(15 \%$ vs $1 \%) .{ }^{4}$ The study carried out by E Orji $(16.21 \%$ vs $34.80 \%$ ) had contradictory findings with caesarean rate more in multigravidae. ${ }^{3}$ This can be because of the racial and ethnic differences and also due to hesitation in augmentation of labour in multigravidae due to risk of rupture as stated in study of Orji E. ${ }^{3}$ In the study of Kunal Shinde et al the overall caesarean rate was $10 \%$ when 50 primigravidae and 50 multigravidae were studied for labour progress using a Modified WHO partograph. ${ }^{5}$

In study by Shrotri AN et al, 5.7\% primigravidae required caesarean section and $79.9 \%$ delivered vaginally, while their cervical plots remained to the left of alert line. ${ }^{7}$ The rate of caesarean was higher in the present study as no instrumental intervention was given place.

In the present study, out of the 70 plots crossing the alert line, $9(12.85 \%)$ underwent caesarean section due to fetal distress and 61(87.14\%) delivered vaginally. Fifty were augmented and delivered vaginally. In Shrotri AN et al, the rate of caesarean was $26.7 \%$ once alert line was crossed. $^{7}$ The rate was similar for Drouin et al. ${ }^{6}$

Out of the total 9 plots crossing the action line, 6 primigravidae were already augmented but underwent caesarean section for non-progression. One multigravida was augmented but underwent caesarean section for nonprogression. Most augmented labours were among primigravidae which suggest a slower rate of progress of labour.

In the study by Drouin et al, caesarean section was performed in $1.3 \%$ women who were too left of alert line, in $26.7 \%$ after crossing the alert line and in $72 \%$ after crossing the action line. ${ }^{6}$

Neonatal asphyxia occurred more in primigravidae $(8.87 \%$ vs $1.61 \%)$ irrespective of the pattern of labour progress which indicates that fetal monitoring should be done more vigilantly in primigravidae in all stages of labour. In the present study, the greater $(14.51 \%$ vs $3.22 \%$ ) NICU admission rate in primigravidae than in multigravidae was similar to that in the study of Malkiel et al $(15.7 \%$ vs $0 \%){ }^{10}$ The reasons for the higher NICU admission in primigravidae in the present study are the associated higher rate of neonatal asphyxia and slower progress of labour.

\section{CONCLUSIONS}

In conclusion, graphic record of labour by means of modified WHO paragraph increases the quality and regularity of observations in the mother and fetus. In addition it provides early warning for the abnormal progress and assists in early decision for referral, interventions and termination of labour.

Though we know that the progress of the labour is slower in the primigravidae than the multigravidae, this study helps to graphically prove the same .It also defies the conclusion of the studies that concluded more caesarean section rates in multigravidae, probably due to the racial and ethnic differences along with the different labour management protocols in execution. The study also reiterates the fact that an institutional delivery with close monitoring is must in the primigravidae who are at a greater risk to deviate from the normalcy.

Though the sample size was the limitation of this study, it sets a platform for carrying out larger studies to support the conclusions.

\section{Funding: No funding sources \\ Conflict of interest: None declared \\ Ethical approval: The study was approved by the Institutional Ethics Committee}

\section{REFERENCES}

1. WHO. World Health Organisation partograph in the management of labour. Lancet. 1994;343:1399-404.

2. Kwast BE, Poovan P, Vera E, Kohls E. The modified WHO partograph: do we need a latent phase African Journal of Midwifery and Women's Health. 2008;2:143-8. 
3. Orji E. Evaluating progress of labour in nulliparasand multiparas using WHO Modified partograph: International Journal of Obstetrics and Gynaecology. 2008;102(3):249-52.

4. Hashim N, Naqvi S, Khanam M, Jafry HF. Journal Pakistan Medical Association. 2012;62:694.

5. Shinde KK, Bangal VB, Singh RK. Study of course of labour by Modified WHO partograph International Journal of Biomedical and advance research. 2012;03:391-6.

6. Drouin P, Nasah BT, Nkounawa F. Value of partograph in management of labour. Obs Gynae. 1979;53:741-5.

7. Shrotri AN. Early recognition of abnormal labor in primigravidae Journal of Obs Gyn of India. 1991;41(3).

8. Friedman EA. Primigravidae labour,A graphic And Statistical analysis. Obst Gynecol.1955;6:567-99.
9. Ijaiya MA, Aboyeji AP, Fakeye OO, Balogun OR, Nwachukwu DC, Abiodun MO. Pattern of cervical dilatation among parturients in Ilorin, Nigeria. Ann Afr Med. 2009;8:181-4.

10. Avishay Malkiel, Pnina Mor RN, Haim Aloni, Efraim Gdansky, Sorina Grisaru-Granovsky. Primiparity: A Traditional Intrapartum Obstetric Risk Reconfirmed. Israel Medical Association Journal. 2008;10:508-11

11. Zhang J, Troendle J, Mikolajczyk R, Sundaram R, Beaver J, Fraser W, Reassessing labor curve in nulliparous women- Am J OG. 2002:115,4,705-10.

Cite this article as: Shah N, Maitra N, Pagi SL. Evaluating role of parity in progress of labour and its outcome using modified WHO partograph. Int J Reprod Contracept Obstet Gynecol 2016;5:860-3. 